ARTICLE

\title{
The evolution of monsters in children's literature
}

\author{
Lauren Christie ${ }^{1 凶}$
}

\begin{abstract}
The Evolution of Monsters in Children's Literature' will chart the developing form of the monster in literature for young people and discuss ways in which different guises can alter the fear experienced by the reader. Literary monsters must continuously adapt according to the developing maturity of the reader to ensure a consistent balance of fear and imagination. In order to approach the subject of fear and monsters in children's literature, and potential reasons behind their presence, this article will explore a wealth of issues such as: the impact of different formats (visual or text only), specific attributes or qualities that can evoke fear from the reader, and the monster as both comical and fearful. Fear in society is typically heightened when faced with the unknown entities of the future. Therefore, this article will conclude by considering the form of future monsters in order to represent this shift in anxiety and potential forms that the monster is yet to adopt.
\end{abstract}

\footnotetext{
${ }^{1}$ University of Dundee, Dundee, UK. ${ }^{凶}$ email: I.u.christie@dundee.ac.uk
} 


\section{Introduction}

M onsters that we create or are exposed to in early childhood can often linger in the memory and imagination of an individual due to a personalisation of fear. Older children commonly use this fear as the foundation upon which to develop their bravery in order to confront their monster in later childhood, or later life. Combine this with imagination, and the result is a potent mixture of adrenaline, excitement and nightmares. Tracking the evolution of the monstrous figure, this article will examine the appearance of selected monsters in literature aimed at younger readers. Frankenstein's creature learned the necessity of development and education in order to ensure survival. Likewise, literary monsters must continuously evolve and adapt with the maturity of the reader in order to maintain a balance of fear and imagination.

Our general understanding of the term 'monster' has shifted over the years due to a variety of literary examples which highlight the fluidity of this form. This figure can often be found championing good over evil, one that is able to help a child through turbulent issues, or as a comrade setting out to accompany them on great adventures. Jeffrey Jerome Cohen defines monsters as, 'disturbing hybrids whose externally incoherent bodies resist attempts to include them in any systematic structuration. And so the monster is dangerous, a form suspended between forms that threatens to smash distinctions' (1996, p. 6). As this article will argue, Cohen recognises that it is the very essence of inconsistency of any 'systematic structuration' that make monsters so effective, so frightening and therefore so memorable to a young person. It can be argued that although most adults would find this fluid form particularly terrifying, children could potentially consider this a challenge-the necessity to recognise the monster and identify its shifting appearance contributes to a sense of adventure.

Instances where 'happy' monsters are introduced to young children as brightly illustrated and over-exaggerated, often results in the child creating an association between the monster and a happy ending (therefore viewing this figure as non-threatening). This article will analyse a sample of monsters which represent the shift between a figure that is comical and brightly illustrated, to one that can be viewed as a genuine threat. It is only through charting this rapidly transforming figure that one is able to identify ways in which the monster can be understood as a beneficial, healthy addition to the typical developmental pattern of a child's imagination.

Each segment of this article will examine different portrayals of the monster, either through appearance, different book formats, or through a change in tone. The first section, 'Monsters and Imagination' will focus on the appearance of the monstrous figure across different formats and targeted towards very young children. This will include an examination of pop-up books, picture books and chapter books. Analysing the portrayal of popular monsters for a young readership will allow for an identification of trends and attributes which are commonly adopted at this early stage. In order to examine the impact that this figure has on a child at such an early stage, each monster will be considered through the lens of typical imaginative development. This article will argue that an early introduction to monsters allows the child to fully explore and develop their imagination-they are completely immersed in a world of make-believe.

The next section, 'The Monstrous Form', will identify the transformation of tone and physical form between the monster that is present in younger picture books, and the form of the monster in children's chapter books. As the child ages, they often become more aware of the dangers that surround them. The gothic genre offers the reader an opportunity to explore anxieties and concerns through the safety of fiction-monsters serve exactly the same purpose for children. Attributes such as a more sinister tone, or a realistic appearance are integrated within children's chapter books in order to reflect a shift in maturity of the reader and their growing awareness of danger. The presence of monsters in children's literature has received a mixed reaction from adults and critics. Critic Janet Evans argues:

Many adults feel that challenging and controversial picture books are not suitable for children... In reality, many young children have to deal with troubling, personal problems on a day-to-day basis... we cannot and should not 'wrap them up in cotton wool'... picture books can help children relate to, and come to terms with, troubling, disturbing and sometimes controversial issues in life (2015, pp. 5-6).

As Evans observes, despite the controversial reception of monsters in children's literature, they are a necessary tool as children attempt to navigate their way through challenging periods of their lives. Although monsters have always been present in children's literature, and will likely continue to exist in this manner, it is important to champion the positive impact that this figure can have on the growth of a child's imagination and as a therapeutic tool for which a child can rely on. Therefore, this section will explore reasons why exposure to this figure remains a healthy and vital process in their maturational journey.

This article will conclude with 'Monsters of Reality' which is aimed at exploring the representation of monsters in young adult fiction through issues such as human evil, paranoia and war. The presence of a monster in this form can be equally terrifying and beneficial for a young adult; although they depict the reality of human evil in the world, the fictional status of the monster can help the reader delve deeper into this cruelty in order to assert a level of understanding about the world. This monster can often help readers study issues such as bullying or depression, once more embodying real-life struggles that children and teenagers will often face.

If monstrous figures stereotypically represent societal anxieties, or fears projected from a parent onto a child, this article will conclude by considering whether or not monsters of the future will continue to develop into manifestations of contemporary concerns, or whether they will return to their gothic roots of a grotesque, over-exaggerated appearance. One factor which has remained consistent across different generations is the monster's ability to offer a fictional, bibliotherapeutic space for the reader. It is only here that the child is able to experience the worst-case scenario of any given situation, the darkest fears within the deep corners of their mind and remain within control of the situation -they can close the book if necessary.

\section{Monsters and imagination}

The monsters selected for analysis throughout this article are all presented in their original form and are figures that are introduced to children at a very young age. Such monsters are frequently the substance of bedtime stories, complete with graphic imagery and detailed description of often horrific and sinister actions. How is it possible therefore to approach this figure and incorporate it into literature for children without traumatising them?

For young children, story worlds and characters are often presented to them when combined with imagined adventures, faraway lands, and mysterious creatures, as J.R.R. Tolkien highlights in his essay 'On Fairy Stories', 'The realm of fairy-story is wide and deep and high and filled with many things... shoreless seas and stars uncounted... it is dangerous... to ask too many questions, lest the gates should be shut and the keys be lost' (2014, p. 27). This quotation, taken from a lecture delivered in 1939, expresses the necessity of combining fantastical creatures, literature and 
imagination. Tolkien compares the power of fairy-stories and imagination, accurately emphasising the important role that both have to play in children's literature. By doing so, the author opens a gateway that allows the child to immerse themselves in a unique storyland. Although this land is frequented by monsters and goblins, and other forms of scary creatures, the child can also imagine themselves as a warrior, equipped with all of the resources necessary to battle these fearsome creatures.

In picture books and board books that are published for younger readers, there are many examples of monsters that are conveyed through bright illustrations and friendly, non-threatening behaviour, such as the monster in Tom Fletcher's There's a Monster in Your Book (2017). One of the most prominent examples of a story that combines monsters, imagination and adventure is Maurice Sendak's Where the Wild Things Are (2000). Sendak's story reads as an homage to childhood imagination. The narration conveys the absolute certainty of imagination within a child's mind-to an adult it may seem impossible, but to the protagonist Max, these events occurred in real life. This story depicts a brave young boy entering a land full of mysterious creatures, 'the place where the wild things are', (2000, p. 17) and gains control of them, 'with [a] magic trick' (2000, p. 19). Prior to this, Max's parents send him to his room due to his naughty behaviour-a room that later transforms into a jungle, riddled with fearful creatures.

Once he has entered this fantastical land, Max encounters the fearful creatures, 'the wild things': 'They roared their terrible roars and gnashed their terrible teeth and rolled their terrible eyes and showed their terrible claws' (2000, pp. 17-18). This extract depicts the importance of repetition and the use of language in picture books to help the young reader develop; in this instance, repetition of the word 'terrible' (with emphasis on the animalistic sounding letter ' $r$ ') helps the child to read and pronounce a challenging word. Despite the focus on their terrible jaws and terrible claws, at no point is it implied that Max is intimidated or afraid of them, thereby allowing the young reader to associate something potentially threatening with something positive.

Moving away from monsters constructed entirely from the imagination, the purpose of the monster evolves in Chae Strathie's picture book Jumblebum (2012) and Julia Donaldson's The Gruffalo (1999). Strathie's employment of the Jumblebum monster is consequential of Johnny's messy room where the creature consists of dirty clothes and general mess. In Jumblebum Strathie appears to be returning to the origins of the monster, a figure that is used as a scare tactic in order to highlight an underlying issue. This picture book consists of various scenarios that are considered relatable to children: a messy bedroom, a young protagonist, and a fear of the dark. As the tale progresses, Johnny discovers the ramifications of his lazy actions, as, late one night, his bedroom awakes the 'horribly, slobbery JUMBLEBUM BEAST!' (2012, p. 9). Threatening to eat Johnny, the monster is described to the reader as possessing a body which consists of:

Wrinkled-up clothes,

All grubby and gross

from its head to its toes.

Its hot stinky breath

reeked of smelly old shoes,

And out of its mouth

leaked a luminous OOZE (2012, p. 9).
An over-exaggerated and detailed description enables Strathie to evoke both fear and wonder from the child reader; fear through the scary monster and wonder through the fact that such a monster exists in the first place. After the resolution of the story where Johnny succeeds in defeating the Jumblebum monster by luring it into the washing machine (a further example of underlying morals), the story concludes with the narrator directly addressing the young reader through a rhyming couplet,

And you would be wise to listen to Mum-

Just in case that wasn't the last

JUMBLEBUM! (2012, p. 24).

In this extract, Strathie's intentions behind creating both the monster and the story are clear. Additionally, with a combination of colourful illustrations and a rhythmic nature, these features are more likely to capture the attention of children throughout the story.

Having previously analysed examples where a monster is used to embody the epitome of imagination and adventure, and also as a cautionary tactic, the last examination will present a monster where the sole purpose is to explore fear surrounding the nature of its existence. In Julia Donaldson's story, the 'Gruffalo' is an imaginary beast that the young mouse refers to in order to inject fear into a variety of threatening animals that live in the woods for self-defence. Ambiguity for the reader as to whether or not the Gruffalo actually exists is maintained right up until the conclusion, where the mouse encounters the dreaded Gruffalo. As such, this story relies on the build-up of suspense, a memorable rhyming scheme, and an example of the difference between the threat of the idea of the monster versus the reality of its presence. The young reader is therefore left in suspense regarding the physical appearance of this monster as they attempt to piece together the characteristics which are gradually revealed:

"A gruffalo? What's a gruffalo?"

“A gruffalo! Why, didn't you know?"

"He has terrible tusks, and terrible claws, and terrible teeth in his terrible jaws."

"Where are you meeting him?"

"Here, by these rocks,

And his favourite food is roasted fox!" (1999, pp. 2-3).

In this extract Donaldson emulates the use of the word 'terrible' from Where the Wild Things Are, in order to place a similar emphasis on the letter ' $r$ '. Employing a simplistic rhyming scheme throughout this text succeeds in building in a natural flow to the writing as the mouse conveys the story of a dangerous Gruffalo. Once the story concludes, the mouse realises that the fictional warnings that he has been relaying are, in fact, reality:

But who is this creature with terrible claws...

He has knobbly knees and turned-out toes

And a poisonous wart at the end of his nose.

His eyes are orange, his tongue is black;

He has purple prickles all over his back. 


\section{"Oh help! Oh no!}

It's a gruffalo!” (1999, pp. 13-14).

At this moment of realisation, rather than expressing signs of fear, the mouse reverses these feelings and explains to the Gruffalo reasons why it is the mouse that should be feared. This is furthered as the mouse strategically walks the Gruffalo back through the woods; although other creatures fear the Gruffalo, the mouse convinces the monster that they are instead afraid of him. This story is not only memorable and attractive for younger readers as the physical features and suspense of the Gruffalo creates excitement, but also through the underlying message that bravery can conquer fear.

Children's picture books and pop-up books that focus on the monster as one of the primary antagonists, are often equipped with a memorable rhythmic scheme, and rhyming couplets. Therefore, rather than hindering the child's educational and emotional maturation, the monster strengthens their imagination. The aforementioned examples evince ways in which their inclusion can not only help build upon a child's imagination (as with Where the Wild Things Are) but through use of colourful illustrations and strategic literary formation, can help with a child's language development. Furthermore, if they are presented in a way which is frightening to a child, as with Jumblebum, this encourages the child to acknowledge and confront this fear.

For children, scary monsters and frightening stories remain memorable as they themselves age. This is achieved through the presentation of material and characters that awaken equal measures of adrenaline and imagination. If children believe they have the resources necessary to battle the monster, then its presence becomes less threatening. Neil Gaiman explains the importance of retaining imagination beyond childhood as being a vital factor in the origins and development of ideas, 'We all-adults and children, writers and readers-have an obligation to daydream. We have an obligation to imagine... the truth is, individuals change their world over and over, individuals make the future, and they do it by imagining that things can be different' (2013, Lines 258-261). Regardless of whether the reader is a child or an adult, imagination and made-up monsters allow the reader to escape the fear of the everyday, and confront their own anxieties in a fictional or imaginary environment. Literature in this form serves the purpose of a security measure for the reader-offering them a space in which to detach from reality, and enter an imaginary realm full of fear, monsters and adventure. Greg Ruth argues:

The kids are already scared, so let's give them some tools to cope with it beyond telling them not to worry about it all... scary stories tell kids there's always something worse, and in effect come across as more honest... Scary tales don't warp kids; they give them a place to blow off steam while they are being warped by everything else (2014, Lines 32-36).

Ruth's theory of embracing fear in this bibliotherapeutic manner signifies one of the most important justifications for including monsters in children's literature. Moreover, this complements Tolkien's belief regarding the power of imagination in fairy-stories, and its significance within a child's education. Children must engage their own imagination and experience imaginary adventures with these fictional monsters in order to build resilience for real life. It is crucial not to question the depths of one's own imagination, for fear of losing the ability to believe.

In order for monsters to remain frightening to children as they age, it is imperative that they must likewise evolve in both appearance and behaviour. Fairy tales and stories as a performative art come to life when combined with monsters and frightening tropes. Introducing his novel (first published in 1981)
Scary Stories to Tell in the Dark, Alvin Schwartz explains the allure towards monsters:

Telling scary stories is something people have done for thousands of years, for most of us like being scared in that way. Since there isn't any danger, we think it is fun... There are ghost stories. There are tales of witches, devils, bogeymen, zombies, and vampires. There are tales of monstrous creatures and of other dangers. There even are stories that make us laugh at all this scariness (2017, p. 2).

This viewpoint consolidates the previously discussed condition of scary stories as existing to entertain, terrify and amuse. The unusual combination of fear, joy, and laughter is prevalent in children's literature through the figure of the monster and remains one of the main reasons for the popularity of the genre. With this combination of ingredients, one crucial factor requires further analysis due to the beneficial role it plays as a child faces a multitude if challenges throughout life.

In adult horror, the literary monster can often be construed as intentionally pushing the boundaries of expectations, thereby challenging pre-existing tropes. This figure is commonly presented as a friendly, helpful monster, one who represents the voice of the ostracised individual. A striking example of this contrast between monstrous categorisation and vulnerability is through M. R. Carey's 2016 novel, The Girl with all the Gifts. Upon analysing this novel, Lauren Christie observes:

The significance of the "monstrous voice" in this novel is monumental due to the fact it is that of a child... The Girl with all the Gifts is the story of a young child viewed by society and government officials as a monstrous figure... Often, in horror and science fiction, children represent innocence and vulnerability against a background of evil and corruption. The child characters in this novel are crucial to Carey's overall message: criticising the state of humanity (2019, pp. 41-42).

The decision to narrate the novel through Melanie's eyes offers the reader an intimate insight into the brutality experienced by ostracised, so-called monsters. Many issues are highlighted in this novel regarding the portrayal and treatment of the infected children by bringing to light and questioning what makes a monster, a monster? As with Shelley's Frankenstein, the truly monstrous behaviour and actions to come out of this novel is that of human interference and evil, a trait which will be later explored in this article through Ransom Riggs's Miss Peregrine's Home for Peculiar Children (2013).

Monstrous figures and gothic tropes are not isolated to one particular genre or format. Many adult horror authors, such as Stephen King, have crossed format and audience through a reimagining of their work. This proves particularly effective when presenting adult texts, such as King's The Girl Who Loved Tom Gordon (2004) as a pop-up book. Gary Greenberg's Pop-Up Book of Phobias (2006) is particularly emphatic due to the concept behind creating a pop-up format out of individualised fear, thereby animating the particular fear or anxiety by allowing them to literally 'pop out' to the reader bringing that fear to life. Disrupting expectations in this way helps to challenge outdated expectations regarding monsters and children's literature.

\section{The Monstrous Form}

Thus far, this article has established ways in which monsters are presented to children, the impact this can have on their resolve and the importance of imagination. Moving forward, how does this figure evolve for older children's literature? The transition of the reader away from illustrated books and towards text-only 
fiction typically indicates a shift in their reading and learning comprehension. As the reader matures, likewise the monster must mature and evolve in order to remain fearful to older readers. Monsters that older children do not find scary are less likely to have an impact. This is significant because it urges the child to look further into potential reasons behind their fear, whereby uncovering any subconscious anxieties. If monsters are thought of as immature for older readers, they are less likely to gravitate towards literature where the monster serves a bibliotherapeutic purpose. Cohen observes the relationship between anxiety, manifestations and monsters by arguing:

Anxiety manifests itself symptomatically as a cultural fascination with monsters-a fixation that is born of the twin desire to name that which is difficult to apprehend and to domesticate (and therefore disempower) that which threatens. And so the monster appears simultaneously as the demonic disemboweler of slasher films and as a wideeyed, sickeningly cute plush toy for children (1996, p. viii).

Disempowering the monster can offer the reader insight into reasons behind its fearful presence; with this knowledge and understanding the reader strips the creature of its threatening qualities, thus regaining control. When children become older, they are generally less shielded by adults, therefore they are forced to face reality more directly. The world around them can become increasingly darker when they are exposed to sinister events connected with the evil that can occur in reality. If fictional monsters act as a manifestation of this transition, then their existence remains vital in the typical maturational journey of the child; the monster allows the child to confront their darkest fears in a controlled environment.

As a child ages, the fears experienced by a large proportion of parents shifts away from being afraid of the child physically hurting themselves, and often gravitating towards fears of abduction and human evil. Evans discusses this fear in more depth, 'Often this urge to protect seems to be an unconscious way of dealing with the guilt we adults feel about having made the world such a dangerous and endangered place for children' (2015, pp. xvii-xix). This theory can be further interpreted to suggest that the true form of many threats that children face is that of evil and corruption within humanity. An 'urge to protect', as Evans notes, can often result in the danger of over-protecting, thereby projecting the fear adults face onto children. This viewpoint is furthered, with Cohen arguing that, 'the monster is born only at this metaphoric crossroads, as an embodiment of a certain cultural moment-of a time, a feeling, a place... the monstrous body is pure culture. A construct and a projection... the monster signifies something other than itself: it is always a displacement' (1996, p. 4). An adult, therefore, who is terrified of spiders, for example, will generally exhibit symptoms of their fear if a spider is present. If this happens within the company of a child, they will begin to relate spiders as scary and dangerous creatures, because they observe the fear displayed from the adult.

The monster in A.F. Harrold's novel The Imaginary (2015) is presented to the child reader as an adult that feeds on the imaginary friends belonging to children. This form represents not only the threat depicted by adults towards children, but when considering manifestations of anxieties can be analysed as representing the necessity of ageing, fear of the unknown and fear of losing the adults in their own life through death. Numerous examples throughout this novel stress Harrold's emphasis on the importance of children retaining imagination, such as the many adventures between Amanda and her imaginary friend. However, this childhood idealism is destroyed with the introduction of the monster of the novel, Mr. Bunting, a predator who sucks the souls of imaginaries. Upon their first close encounter with Mr. Bunting, Harrold emphasises the cold, detached nature of this monster:
A cold hand snapped round his wrist... the man, Mr. Bunting... opened his mouth up... unhinged it almost, snake-like... Rudger saw that Mr. Bunting's teeth weren't like those of a normal person... they ran back and back into his head in neat rows... Mr. Bunting's mouth had become a pit, a hole, a shaft or well that he was on the very edge of falling into (2015, pp. 66-69).

In this extract, Bunting's predatory nature becomes clear to a child reader. The brutality of the 'cold hand' grabbing Rudger, and the horrors to be found deep within the mouth and soul of the creature instils a sense of fear in the reader, furthering the monstrous depiction of this character. This continues further into the novel as Harrold details Bunting's feeding process, 'Mr. Bunting had his eyes shut. This was his favourite moment of all. He savoured the feeding, the flavour, the taste of the imaginaries as he swallowed. They wriggled as they went down. Their fear and panic added spice. It made him feel whole, complete, satisfied' (2015, p. 206). Dehumanisation is present in this extract through the graphic description of Bunting's feeding process. Use of language to describe the imaginaries as wriggling down his throat as he feeds completes the monstrous depiction.

The concept of monsters in an adult form who feed from the souls of children is not isolated to The Imaginary. For example, the dementors in J. K. Rowling's Harry Potter and the Prisoner of Azkaban (1999) serve the same punishment. From this novel it is significant to note the description of the dementors to the young reader, 'Standing in the doorway... was a cloaked figure that towered to the ceiling. Its face was completely hidden beneath its hood... there was a hand protruding from the cloak and it was glistening, grey-ish, slimy-looking... like something dead that had decayed in water' (1999, p. 66). Rowling's dementors offer the most fitting example of monsters which are presented without any obvious appearance, any description, urging the reader to apply whatever qualities they consider fearful. This transitional series offers literature which can be viewed as closing the gap between children's fiction and young adult fiction (literature which gradually darkens to coincide with the ageing and maturity of the reader). In this description, without any mention of the face, the monster remains shrouded in mystery; however, the magnitude of its cloaked appearance, obscuring any details for the reader, and the hand resembling decay and death offers enough substance to ignite the imagination and fear of the reader.

Monsters also resemble human form in Neil Gaiman's The Graveyard Book (2009). Similar to Lord Voldemort's destruction of Harry Potter's family, The Graveyard Book opens with the dramatic murder of Nobody Owens' family,

There was a hand in the darkness, and it held a knife. The knife had a handle of polished black bone, and a blade finer and sharper than any razor... the street door was still open, just a little, where the knife and the man who held it had slipped in, and wisps of night-time mist slithered and twined into the house (2009, pp. 1-4).

Such a dramatic introduction immediately alerts the reader to danger, malicious intent and the commonly held fear of home invasion. In this novel, Gaiman intentionally introduces mystery and danger before disclosing information on the threat itself, "The man Jack... wiped off the knife and his gloved right hand... the hunt was almost over. He had left the woman in her bed, the man on the bedroom floor, the older child in her brightly coloured bedroom, surrounded by toys and half-finished models. That only left the little one, a baby' $(2009$, p. 6). This extract contains enough information to inform the reader that the 'man Jack' has broken into this house and callously killed all of the family, with the exception of the baby. As this remains an older children's book, Gaiman details this event 
without providing a graphic description, a tactic which strengthens the reader's ability to engage their imagination.

Several things about the slaughter of this family appear to grotesquely contrast the fact that this novel is intended to be read by a younger audience. Firstly, use of the word 'hunt' as Jack is killing individual members of the family dehumanises the monster even further, stripping the victims and the monster of any sense of humanity and instead, relating them to animalistic predator and prey; their location upon death (for example the child with her 'brightly coloured room' and toys, reminding the reader of her young age); and finally the predatory nature of a killer roaming through the house in order to locate and kill a vulnerable baby.

With an emphasis placed on building terror for the reader in older children's literature, the literary monster remains beneficial to the child reader as their awareness of danger increases. This offers young readers the opportunity to strengthen their own resilience through battling this new, mature and evil figure. Through the aforementioned examples, it is apparent that the monster naturally evolves in order to reflect a changing level and type of fear as experienced by the child. A grotesque appearance, inarticulate expression, and threatening presence is no longer frightening to a slightly older audience. However, a figure that they cannot identify generates a new level of terror.

\section{Monsters of the mind}

If monsters disguised as humans are to be considered transitional figures of fear between childhood and adolescence, what form must the monster take moving closer towards young adult and adult fiction? The striking quality of this monstrous form in evoking fear from the reader is due to the minimal information provided for suggested appearance, and a greater reliance on personalised fear from residual trauma or subconscious terror. Despite the significantly darker tone generated from these monsters, they remain a healthy factor in the development and transitional journey as young adult readers age. This monster, although sinister in intent, remains fictional, therefore enabling the reader to fictionally explore a fear or anxiety. As Stephen King notes when describing the presence of his monstrous characters, 'We sometimes need to create unreal monsters... to stand for all the things we fear in our real lives: the parent who punches instead of kissing... none shine so bright as the acts of cruelty we sometimes perpetrate in our own families' (2001, p. xii). The monsters in young adult literature and adult horror are uncannily human, often pure evil and are primarily intended to generate fear from the reader. The reason they pose such a threat to the reader is the fact that they are evil monsters in a human disguise.

A monster without any obvious appearance can wreak havoc in the minds of vulnerable readers. Aaron Mahnke notes the shift in content between children's and young adult fiction towards adult horror as the fact that, 'We tell so many stories of beings that are almost human, but not quite... it seems the more they resemble us, the more frightening they become' (2017, p. 143). This creature is evident in Josh Malerman's novel, Birdbox, which explores the monster as an unknown entity, thus relying on the madness of mass hysteria, 'Man is the creature he fears... there is activity on the banks. Man, animal, monster... details are added to a body and a shape that you have no concept of. To a face that might have no face at all. The creatures of her mind walk... they stand outside the windows... they observe' (2015, p. 273). In the novel, it transpires that the monster feared most of all by these individuals is their own mind. As this article has demonstrated, the monstrous figure develops and matures with the reader. In young adult fiction, there is a notable lack of the suggested monstrous appearance, and a heavier reliance on one's own imagination. This conjures the darkness of personalised fear for each reader. In young adult and adult fiction, there is often nothing more terrifying than that which cannot be identified. We know the monster represents danger, but if we know not what to look out for, how do we know when we are in peril?

In Miss Peregrine's Home for Peculiar Children, the monster is presented to the reader as a multi-layered concept. On the surface, Riggs has created fictional monsters (hollows and wights) that threaten to consume the souls of the peculiar children. However, Riggs's integration of the protagonist's grandfather (Abraham) creates a secondary representation of evil and monstrosity, as he is a Jewish survivor of the Holocaust. As Abraham shares his memories and experiences from the Second World War, Riggs urges the reader to additionally consider monsters within humanity.

The metaphorical connection between monsters and human evil has been noted and debated amongst numerous horror critics, as Judith Halberstam observes, 'Monstrosity as the bodily manifestation of evil makes evil into a local effect... we have seen, in Nazi Germany and elsewhere, that... evil stretches across cultural and political productions as complicity and collaboration and it manifests itself as a seamless norm rather than as some monstrous disruption' (1995, p. 162). Upon reflection, this connection between the human evil of Nazi Germany and monsters more broadly consolidates not only the shift in tone between young adult literature and adult horror, but also the darkening form of the evolving monster. As Riggs observes, 'these weren't the kind of monsters that had tentacles and rotting skin... they were monsters with human faces, in crisp uniforms... so banal you don't recognise them' (2013, p. 21). The monsters in Riggs' novel represent the horrors within humanity and the reality of violence, through a shift in form from something imaginary, to something human.

In this novel, both hollows (their full name being 'hollowgasts', again creating a connection with the Holocaust), and wights, are depicted as dangerous creatures that feed on the souls of peculiars, 'Rather than becoming gods, they had transformed themselves into devils... if being a hollow is a living hell... then being a wight is akin to purgatory... though wights aren't as strong... as hollows, they're often just as dangerous... and are often able to blend into the general population. It can be difficult to distinguish them from common folk' (2013, pp. 260-261). Hollowgasts, or 'hollows', are terrifying for children as they are a physical embodiment of many monstrous qualities that children conjure from their own imagination. One monster is described as '[staring] back with eyes that swam in dark liquid, furrowed trenches of carbon-black flesh loose on its hunched frame, its mouth hinged open grotesquely so that a mass of long eel-like tongues could wriggle out' (2013, p. 37). Despite the imaginative qualities that hollows possess, wights are potentially more terrifying as they are able to take human form, thus blending into society and threatening the safe space of a child.

As demonstrated throughout this article, the monstrous form possesses the ability to evolve in relation to the audience. Authors can adapt this figure to suit everything, from a friendly and harmless creature to a monstrous embodiment of antisemitism. What form can we expect from monsters of future generations? Contemporary young adult fiction is rife with examples of monsters that have evolved from or survived a variety of world-wide disasters or national emergencies; monsters in this genre reflect a wide range of anxieties, from the effects of climate crisis to terrorism. Halberstam concludes her argument by considering this shift in form of contemporary monsters:

Monsters within postmodernism are already inside-the house, the body, the head, the skin, the nation... Monsters of the nineteenth century-like Frankenstein, like Dracula - certainly still scare and chill but they scare us from a distance. We wear modern monsters like skin, they are us, 
they are on us and in us. Monstrosity... is replaced with a banality... because the enemy becomes harder to locate and looks more like the hero (1995, pp. 162-163).

Halberstam argues that it is the banality of contemporary monsters that generates anxiety for young readers. If creatures that are physically monstrous no longer terrify, then the natural evolution is towards monsters masquerading as human, or indeed, exposure of the monstrous qualities of humanity. Young adult fiction, perhaps more so than children's fiction, thrives on exploring post-apocalyptic and dystopian environments. This setting reflects the anxieties of younger generations as they become more informed on issues such as climate crisis, or economic and political instability. The ability to explore a 'worst case scenario' situation through young adult fiction enables the author to consider what kind of monster would remain terrifying. Zombies, artificially altered creatures, and disfigured monsters are often the only creatures that are left behind in this new world. Monsters that terrify, creatures that have survived the apocalypse, are all an embodiment of the unknown. If humanity is collectively uncertain about the stability of their own future through the instability of the planet or through the increase of mass killings, naturally future monsters would represent a projection of this fear and uncertainty. Children's literature historically creates monsters that reflect cultural anxieties; therefore, it stands to reason that this reflection will continue for future generations of both monsters and readers.

This article has highlighted the different forms of the monster through a selection of specific examples taken from children's and young adult literature. As children age, they can be exposed to threats in a variety of different forms. To remain relevant, fearful and at times therapeutic, it is vital that the monster evolves with the reader. It is important that the monster remains capable of generating fear, as it is through this process that the child or young adult is able to explore boundaries and tolerances, and experience repressed anxieties. The novels analysed throughout this article all examine different portrayals of the monster. What remains consistent is the monstrous representation of a fear either built through imagination or projected onto the child from an adult. Therefore, to share this style of literature with an adult offers an opportunity for honest discussion and participation; offering a shared experience of mutual fears in order to create bonding between adult and child. Chloe Germaine Buckley observes that 'the Gothic helps children grow up' (2018, p. 18). What becomes interesting is the similarity in the threat of the adult within the fears of both children and parents. This prompts a further examination of the portrayal of monsters within adult horror novels, and the presence of the evil of mankind within contemporary society.

As most children age, for a while they are often confident in their ability to tackle any hurdles or challenges they may face. They remain positive of this as they are frequently equipped with imaginary friends, their toys and bears, and an unlimited abundance of optimism. The monster remains present alongside the child's imaginary friends and toys as the child ages, it represents a wellrounded package of imagination and fear. Once the child becomes a young adult, and eventually an adult they often lose the power of imagination, the support they received from toys and teddies and eventually, the inbuilt optimism. It is once these qualities begin to fade and the monster remains that the real fear sets in; without a toolbox of equipment with which to challenge the monster, the individual is often left lonely and frightened. It is when the individual finds themselves in this state of existence that the literary monster must be combined with positive qualities in order to help the individual rediscover their lost imagination and lost sense of positivity. It is through maintaining a consistent balance of imagination, fear, monsters and wonder that the child, young adult and adult is truly able to confront whatever situation they may encounter in real life. It is through belief in the impossible in a fictional environment, that the situation in reality becomes possible.

Received: 28 November 2019; Accepted: 19 February 2020;

Published online: 17 March 2020

\section{References}

Buckley C (2018) Twenty-first-century children's gothic: from the wanderer to nomadic subject. Edinburgh University Press, Edinburgh

Christie L (2019) The monstrous voice: M. R. Carey's The Girl with all the Gifts. In: Kupferman D, Gibbons A (eds) Childhood, science fiction and pedagogy: children ex machina. Springer, Singapore, pp 41-56

Cohen J (1996) Monster theory: reading culture. University of Minnesota press, Minneapolis

Donaldson J (1999) The gruffalo. Macmillan Children's Books, London

Evans J (2015) Challenging and controversial picture books: creative and critical responses to visual texts. Routledge, London

Fletcher T (2017) There's a monster in your book. Random House, New York

Gaiman N (2009) The graveyard book. Bloomsbury, London

Gaiman N (2013) Why our future depends on libraries, reading and daydreaming The Guardian. https://www.theguardian.com/books/2013/oct/15/neil-gaimanfuture-libraries-reading-daydreaming. Accessed 12 Nov 2019

Greenberg G (2006) Pop-up book of phobias. Harper Collins, New York

Halberstam J (1995) Skin shows: gothic horror and the technology of monsters. Duke University Press, North Carolina

Harrold A (2015) The imaginary. Bloomsbury, London

King S (2001) The shining. Hodder and Stoughton, London

King S (2004) The girl who loved Tom Gordon. Simon \& Schuster Children's, London

Mahnke A (2017) The world of lore: monstrous creatures. Wildfire, London

Malerman J (2015) Birdbox. Harper Voyage, London

Riggs R (2013) Miss Peregrine's home for peculiar children. Quirk Books, Philadelphia

Rowling JK (1999) Harry Potter and the prisoner of Azkaban. Bloomsbury, London Ruth G (2014) Why horror is good for you (and even better for your kids). Tor. Com. https://www.tor.com/2014/05/29/why-horror-is-good-for-you-andeven-better-for-your-kids/. Accessed 4 Nov 2019

Schwartz A (2017) Scary stories to tell in the dark. Harper Collins, New York

Sendak M (2000) Where the wild things are. Red Fox, London

Strathie C (2012) Jumblebum. Scholastic Children's Books, London

Tolkien JRR (2014) On Fairy-Stories. In: Flieger V, Anderson D (eds) On fairystories: expanded edition with commentary and notes. Harper Collins, New York

\section{Competing interests}

The author declares no competing interests.

\section{Additional information}

Correspondence and requests for materials should be addressed to L.C.

Reprints and permission information is available at http://www.nature.com/reprints

Publisher's note Springer Nature remains neutral with regard to jurisdictional claims in published maps and institutional affiliations.

\footnotetext{
Open Access This article is licensed under a Creative Commons Ay
adtribution 4.0 International License, which permits use, sharing, appropriate credit to the original author(s) and the source, provide a link to the Creative Commons license, and indicate if changes were made. The images or other third party material in this article are included in the article's Creative Commons license, unless indicated otherwise in a credit line to the material. If material is not included in the article's Creative Commons license and your intended use is not permitted by statutory regulation or exceeds the permitted use, you will need to obtain permission directly from the copyright holder. To view a copy of this license, visit http://creativecommons.org/ licenses/by/4.0/.
}

(C) The Author(s) 2020 